\title{
PENGARUH OBESITAS TERHADAP TERJADINYA DISFUNGSI SEKSUAL PRIA
}

\author{
${ }^{1}$ Zuriaty Hiola \\ ${ }^{2}$ Lydia Tendean \\ ${ }^{2}$ Benny Wantouw \\ ${ }^{1}$ Kandidat Skripsi Fakultas Kedokteran Universitas Sam Ramtulangi \\ ${ }^{2}$ Bagian Biologi Universitas Sam Ratulangi \\ Email: Rya_zuriaty09@yahoo.co.id
}

\begin{abstract}
Obesity is a worldwide problem. WHO has established obesity as a global epidemic because it can lead to various health problems, one of them is male sexual dysfunction. The purpose of this study was to determine the effect of obesity on male sexual dysfunction. The study was conducted in the Hutuo Village, Limboto District, Gorontalo regency with 60 obese men as a sample. This study was an analytical observational study with cross-sectional approaches. Dependent variable in this study is a sexual dysfunction assessed by questionnaire IIEF (International Index of Erectile Function), while the independent variables are obese as measured by body mass index (BMI). Results obtained from 60 obese men in this study, there are 6 people with normal sexual function and 54 people with sexual dysfunction. The majority of obese men with sexual dysfunction is aged 31-40 years (48.3\%) with the highest level of education is high school (33.3\%). The most of them have one person number of children (48.3\%) and the majority had a habit of smoking (55.0\%). Based on the non parametric statistical analysis with Mann Whitney test found that body mass index values have a significant influence on the occurrence of sexual dysfunction, it's seen in the value of $\mathrm{P}=0.021$ with a significance level $(\alpha)=0.025$. From these results it can be concluded that obesity affects to male sexual dysfunction.
\end{abstract}

Keywords: Obesity, sexual dysfunction

\begin{abstract}
Abstrak: Obesitas merupakan suatu permasalahan yang mendunia. WHO telah menetapkan obesitas sebagai epidemik global karena dapat menyebabkan berbagai gangguan kesehatan, salah satunya berupa disfungsi seksual pria. Tujuan penelitian ini adalah untuk mengetahui pengaruh obesitas terhadap terjadinya disfungsi seksual pria. Penelitian dilakukan di Kelurahan Hutuo, Kecamatan Limboto, Kabupaten Gorontalo dengan jumlah sampel sebanyak 60 orang pria obesitas. Penelitian ini merupakan jenis penelitian analitik observasional dengan pendekatan cross-sectional. Variabel tergantung dalam penelitian adalah disfungsi seksual yang dinilai berdasarkan kuesioner IIEF (International Index of Erectile Function) sedangkan variabel bebasnya adalah obesitas yang diukur berdasarkan indeks masa tubuh (IMT). Dari penelitian ini diperoleh hasil bahwa dari 60 pria obesitas terdapat 6 orang dengan fungsi seksual normal dan 54 orang mengalami disfungsi seksual. Sebagian besar pria obesitas dengan disfungsi seksual berada pada usia 31-40 tahun (48,3\%) dengan tingkat pendidikan terbanyak yaitu SMA (33,3 \%). Paling banyak mereka memiliki jumlah anak 1 orang (48,3\%) dan mayoritas mempunyai kebiasaan merokok (55,0\%). Berdasarkan hasil analisis statistik non paramaetrik uji Mann Whitney didapatkan bahwa nilai indeks masa tubuh memberikan pengaruh yang signifikan terhadap terjadinya disfungsi seksual yang terlihat pada nilai $\mathrm{P}=0,021$ dengan tingkat signifikansi $(\alpha)=0,025$. Dari hasil penelitian ini dapat disimpulkan bahwa obesitas berpengaruh terhadap terjadinya disfungsi seksual pria.
\end{abstract}

Kata kunci: Obesitas, disfungsi seksual 
Obesitas adalah kondisi penumpukan lemak di jaringan adiposa secara berlebihan yang dapat mengakibatkan gangguan kesehatan. Obesitas pada seseorang dapat diidentifikasi dengan menggunakan IMT (Indeks Masa Tubuh), nilai IMT $\geq 30$ menunjukkan bahwa seseorang mengalami obesitas. $^{1}$

Prevalensi kelebihan berat badan dan obesitas di Indonesia dalam beberapa dekade terakhir cenderung mengalami peningkatan. Menurut Riset Kesehatan Dasar (RISKESDAS) tahun 2010 prevalensi nasional obesitas dan kelebihan berat badan pada penduduk kelompok umur diatas 18 tahun adalah 21,9\%, dengan prevalensi tertinggi berada di provinsi Sulawesi Utara sebesar 37,1\%. ${ }^{2}$

Obesitas dapat dipengaruhi oleh beberapa faktor, salah satunya adalah faktor lingkungan, termasuk didalamnya masalah dalam pemilihan jenis makanan, pola makan, porsi perkali makan dan tingkat aktivitas pada masing-masing individu. ${ }^{3}$

Terdapat penelitian yang menghubungkan antara obesitas dengan disfungsi seksual pada pria. Penelitian yang dilakukan di Eropa membahas tentang kerusakan fisik dan fungsi seksual pria yang mengalami obesitas, didapatkan data bahwa pria dengan BMI $>30 \mathrm{~kg} / \mathrm{m}^{2}$ dan lingkar pinggang > $102 \mathrm{~cm}$ memiliki kemungkinan lebih besar untuk memperlihatkan dua atau lebih gejala yang mengarah pada kerusakan fisik dan gangguan fungsi seksual. ${ }^{4}$

Disfungsi seksual adalah gangguan pada setiap komponen siklus respon seksual, yang menyebabkan fungsi seksual pada tubuh seseorang melemah. Pada pria disfungsi seksual mengacu kepada kesulitan terlibat dalam hubungan seks, meliputi gangguan dalam gairah seks (libido), kemampuan untuk mencapai atau menjaga ereksi (disfungsi ereksi atau impoten), kemampuan untuk mencapai orgasme dan ejakulasi. ${ }^{5}$ Faktor penyebab dari disfungsi seksual diantaranya faktor genetik, hormonal, underlying disease (misalnya DM, hipertesi, stroke dll), dll. ${ }^{6}$
Berdasarkan latar belakang diatas, maka peneliti merasa tertarik untuk melakukan penelitian tentang "Pengaruh Obesitas terhadap terjadinya Disfungsi Seksual Pria”.

\section{METODE PENELITIAN}

Desain penelitian merupakan penelitian survey analitik dengan menggunakan pendekatan cross-sectional. Penelitian dilakukan di Kelurahan Hutuo, Kecamatan Limboto, Kabupaten Gorontalo dalam rentang waktu dari bulan November 2012 sampai Januari 2013. Sampel yang digunakan berjumlah 60 orang, dengan tehnik pengambilan sampel Purposive random sampling dan ditetapkan berdasarkan kriteria inklusi dan eksklusi. Adapun kriteria inklusinya yaitu pria obesitas dengan IMT $\geq 30 \mathrm{~kg} / \mathrm{m}^{2}$, usia 20 45 tahun, telah menikah, memiliki istri dan anak, sehat jasmani, serta bersedia menjadi subjek penelitian, sedangkan yang termasuk dalam kriteria eksklusi yakni pria yang memiliki riwayat penyakit Diabetes Melitus, infertil, trauma akut testis, undesensus testis, klinefelter's syndrome, serta tidak bersedia menjadi subjek penelitian. Variabel yang diteliti dalam penelitian ini yaitu obesitas sebagai variabel bebas dan disfungsi seksual sebagai variabel tergantung. Data primer untuk variabel bebas didapatkan melalui pengukuran tinggi dan berat badan untuk memperoleh nilai indeks masa tubuh masing-masing responden, sedangkan data primer untuk variabel tergantung didapatkan melalui hasil pengisian kuesioner IIEF yang terdiri dari 20 pertanyaan untuk menentukan responden yang mengalami disfungsi seksual dan responden dengan fungsi seksual normal. Analisis statistik menggunakan program SPSS versi 20. Analisis data yang digunakan adalah analisis univariat yang sebelumnya dilakukan uji homogenitas dan analisis 2 Independent Sample uji Mann Whitney untuk menguji hipotesis penelitian secara statistik. 


\section{HASIL DAN PEMBAHASAN}

Jumlah sampel yang diperoleh sebanyak 60 orang. Obesitas berdasarkan IMT dibagi atas obesitas I dan II, masingmasing sebanyak 33 dan 27 orang. Secara keseluruhan hasil dari olah data pada 60 laki-laki obes, didapatkan 6 orang (10\%) dengan fungsi seksual normal dan 54 orang (90\%) lainnya mengalami disfungsi seksual. Sebagian besar responden, yakni pria obesitas dengan disfungsi seksual berusia 31-40 tahun (48,3\%). Kebanyakan responden memiliki tingkat pendidikan SMA (33,3\%) dan memiliki anak berjumlah 1 orang $(48,3 \%)$, selain itu mayoritas responden memiliki kebiasaan merokok (55,0\%) (Tabel 1). Berdasarkan hasil perhitungan statistik uji Mann Whitney, obesitas menunjukkan pengaruh yang bermakna terhadap disfungsi seksual karena diperoleh hasil $\mathrm{P}$ value 0,021 atau $\mathrm{P}$ $<0,025$ (Tabel 2). Hasil yang bermakna diperoleh pula pada hasil uji statistik pengaruh nilai IMT terhadap setiap komponen disfungsi seksual (libido ereksi, orgasme dan ejakulasi), dimana semuanya memiliki nilai $\mathrm{P}<0,025$ (Tabel 3).
Disfungsi seksual merupakan suatu keadaan yang menunjukkan adanya gangguan pada salah satu atau lebih aspek fungsi seksual yang meliputi libido (hasrat seksual), ereksi, orgasme dan ejakulasi. Secara umum disfungsi seksual dipengaruhi oleh beberapa faktor salah satunya adalah obesitas. ${ }^{6}$

Pada tabel 2 dibawah dapat dilihat bahwa semakin tinggi nilai IMT, jumlah responden dengan fungsi seksual normal semakin menurun. Hal ini didukung oleh penelitian yang dilakukan oleh The Health Professionals Follow-up Study pada 22.086 pria di Amerika yang memperlihatkan hubungan jelas antara obesitas dengan salah satu komponen disfungsi seksual yakni disfungsi ereksi.Ddiketahui bahwa obesitas berhubungan dengan rendahnya kadar hormon testosteron dan penurunan kadar sex hormone binding globulin (SHBG) yang berperan dalam fungsi seksual. Dan terbukti setelah dilakukan follow-up selama 14 tahun diperoleh bahwa disfungsi seksual dalam hal ini disfungsi ereksi lebih banyak terjadi pada pria dengan obesitas (odd ratio [OR] 1,7). ${ }^{7}$

Tabel 1. Distribusi sampel pria obesitas dengan disfungsi seksual berdasarkan karakteristik responden

\begin{tabular}{|c|c|c|c|c|}
\hline \multirow{3}{*}{$\begin{array}{c}\text { Karakteristik } \\
\text { Responden }\end{array}$} & \multicolumn{4}{|c|}{ Disfungsi seksual } \\
\hline & \multicolumn{2}{|c|}{ Tidak } & \multicolumn{2}{|c|}{ Ya } \\
\hline & $\mathbf{N}$ & $\%$ & $\mathbf{N}$ & $\%$ \\
\hline \multicolumn{5}{|l|}{ Umur } \\
\hline $20-30$ & 2 & $3,3 \%$ & 11 & $18,3 \%$ \\
\hline $31-40$ & 3 & $5,0 \%$ & 29 & $48,3 \%$ \\
\hline 41-50 & 1 & $1,7 \%$ & 14 & $23,3 \%$ \\
\hline \multicolumn{5}{|l|}{ Pendidikan } \\
\hline SD & 0 & $0 \%$ & 9 & $15 \%$ \\
\hline SMP & 0 & $0 \%$ & 9 & $15 \%$ \\
\hline SMA & 4 & $6,7 \%$ & 20 & 33,3 \% \\
\hline S1 & 1 & $1,7 \%$ & 13 & $21,7 \%$ \\
\hline S2 & 1 & $1,7 \%$ & 3 & $5 \%$ \\
\hline \multicolumn{5}{|l|}{ Jumlah anak } \\
\hline 1 & 1 & $1,7 \%$ & 29 & $48,3 \%$ \\
\hline$\geq 2$ & 5 & $8,3 \%$ & 25 & $41,7 \%$ \\
\hline \multicolumn{5}{|l|}{ Merokok } \\
\hline Tidak & 3 & $5 \%$ & 21 & $35,0 \%$ \\
\hline Ya & 3 & $8,3 \%$ & 33 & $55,0 \%$ \\
\hline
\end{tabular}


Tabel 2. Pengaruh nilai IMT terhadap terjadinya disfungsi seksual

\begin{tabular}{|c|c|c|c|c|c|}
\hline \multirow{3}{*}{$\begin{array}{c}\text { IMT (Indeks Massa } \\
\text { Tubuh) }\end{array}$} & \multicolumn{4}{|c|}{ Disfungsi seksual } & \multirow{3}{*}{$\mathrm{P}$} \\
\hline & \multicolumn{2}{|c|}{ Tidak } & \multicolumn{2}{|c|}{$\mathrm{Ya}$} & \\
\hline & Jumlah & $\%$ & Jumlah & $\%$ & \\
\hline 30-34,9 (Obese I) & 6 & $10 \%$ & 27 & $45 \%$ & \\
\hline 35,0-39,9 (Obese II) & 0 & $0 \%$ & 27 & $45 \%$ & 0,021 \\
\hline TOTAL & 6 & $10 \%$ & 54 & $90 \%$ & \\
\hline
\end{tabular}

Tabel 3. Pengaruh IMT terhadap jumlah terjadinya disfungsi seksual berdasarkan komponen fungsi seksual

\begin{tabular}{ccccc}
\hline $\begin{array}{c}\text { Komponen Fungsi } \\
\text { Seksual }\end{array}$ & Kategori IMT & Normal & $\begin{array}{c}\text { Disfungsi } \\
\text { Seksual }\end{array}$ & P \\
\hline \multirow{2}{*}{ Ereksi } & Obes I & 24 & 9 & 0,000 \\
& Obes II & 5 & 21 & 0,001 \\
\hline \multirow{2}{*}{ Ejakulasi } & Obes I & 21 & 12 & 0,000 \\
& Obes II & 4 & 23 & 0,000 \\
\hline \multirow{2}{*}{ Hasrat sex } & Obes I & 21 & 21 & 25 \\
\hline \multirow{2}{*}{ Orgasme } & Obes II & 2 & 18 & 0,000 \\
\hline \multirow{2}{*}{ Kepuasan Seluruh } & Obes I & 15 & 27 & 10 \\
\hline
\end{tabular}

Disfungsi seksual pada pria obesitas dipicu oleh rendahnya kadar hormon testosteron total, testosteron bebas dan SHBG (Sex Hormone Binding Globulin) yang mereka miliki. Hal ini disebabkan karena adanya peningkatan kadar estrogen, sebagai hasil dari aromatisasi androgen di bagian perifer jaringan adiposa penderita obesitas. ${ }^{8}$ Dengan adanya perubahan kadar hormon tersebut maka akan terjadi penekanan pada jalur hipotalamus hipofisis yang mengakibatkan adanya umpan balik negatif terhadap produksi hormone testosteron yang berperan dalam fungsi seksual pria. ${ }^{9}$ Hal ini yang menyebabkan adanya gambaran karakteristik profil hormon "hyperestrogenic hypogonadotropic hipo- gonadisme" pada pria dengan obesitas. ${ }^{8}$

Pada tabel 3 jumlah terjadinya disfungsi seksual pada setiap komponen fungsi seksual semakin meningkat seiring dengan peningkatan IMT yang dikelompokkan menjadi obes I dan II. Disfungsi ereksi pada pria obesitas disebabkan karena adanya kerusakan pada lapisan pembuluh darah, dalam hal ini endothelium, sehingga fungsinya untuk menghasilkan oksida nitrat yang berperan dalam proses ereksi menjadi terganggu. ${ }^{10}$ Sementara untuk masalah ejakulasi dan hasrat seksual dihubungkan dengan masalah psikologis. Pria yang megalami obesitas sering merasa kurang percaya diri terhadap tubuhnya sendiri, sehingga 
menimbulkan rasa cemas ataupun stress yang menyebabkan seorang pria ingin mencapai orgasme dan ejakulasi secara tergesa-gesa, dan menyebabkan pasangan merasa ridak puas. Lebih jauh, reaksi negatif, yang muncul pada pria dengan ejakulasi dini ialah perasaan takut dan khawatir setiap akan melakukan hubungan seksual. ${ }^{11}$ Hal ini sesuai dengan penelitian yang dilakukan oleh Cornelia Rada dkk, tentang hubungan BMI dan dinamika seksual, diperoleh bahwa terjadi penurunan frekuensi hubungan seksual seiring dengan meningkatnya nilai BMI seseorang yang dibagi seseuai kategori underweight, normal, overweight dan obes. ${ }^{12}$

\section{KESIMPULAN DAN SARAN}

Secara keseluruhan, dari hasil penelitian ini dapat disimpulkan bahwa obesitas berpengaruh signifikan terhadap terjadinya disfungsi seksual pria, dimana semakin tinggi nilai IMT pria, maka akan semakin tinggi pula jumlah terjadinya disfungsi seksual pria. Untuk mengetahui seberapa besar pengaruh obesitas terhadap terjadinya disfungsi seksual pria, perlu dilakukan penelitian lebih lanjut yang dilengkapi dengan pemeriksaan laboratorium kadar testeron darah dan membandingkan hasilnya dengan kuesioner.

\section{DAFTAR PUSTAKA}

1. WHO media centre. Obesity and Overweight. 2012. (http://www.who.int/ mediacentre/factsheets/fs311/en/ di akses pada 15 Oktober 2012)

2. Depkes RI. Laporan Hasil Riset Kesehatan Dasar Indonesia-Tahun 2010. Jakarta:
Badan Penelitian dan Pengembangan Kesehatan Depkes RI. 2011

3. Nugraha IG. Etiologi dan Patofisiologi Obesitas. Dalam: Soegih RR, Wiramihardja KK, penyunting. Obesitas Permasalahan dan Terapi Praktis. Ed.1. Jakarta: CV Sagung Seto, 2009; h.11-12

4. Han S T, Tajar A, O'Neill W T, Jiang M, Bartfai G, Boone S, et al. Clinical Study Impaired Quality of life and sexual function In overweight and obese men: the European Male Ageing Study. EJE. 2011;164:1003.

5. Ellsworth P. 100 tanya jawab mengenai Disfungsi Ereksi. Ed. 2. Jakarta: PT Indeks, 2011; h.25.

6. Wantouw B. Disfungsi seksual pada pria dan penanganannya. BIK Biomed. Oktober-Desember 2007; 3; 199-203.

7. Corona G, Vita de G, Sforza A, Maggi M. Obesity and Erectile Dysfunction. European Urological Review. Italy. 2009

8. Hammoud AO, Gibson M, Peterson M C, Hamilton DB, Careell TD. Minireview Obesity and Male Reproductive Potential. Jandrol. Utah. 2006;27(5):619-625.

9. Dwianti D, Widiastuti R. Hubungan Obesitas dengan Andropause di RSUD PROF. Dr.Margono Soekarjo Purwokerto. Mandala of Health. 2011;5(3).

10. Kaminetsky J. Epidemiology and Pathophysiology of male sexual dysfunction. International Journal of Impotence Research. Nature Publishing Group; 2008.

11. Pangkahila W. Anti-Aging Medicine. Jakarta: Buku Kompas; November 2007.

12. Rada C, Prejbeanu I, Albu A, Manolescu S. Correlation between Body Mass Index and Sexual Dynamics. International Journal of Collaborative Research on Internal Medicine \& Public Health. 2011;3(2):144157. 